\title{
De toetsing van de werking van de interne controle
}

\section{Hans Blokdijk}

$$
1
$$

\section{Inleiding}

In het juninummer 2002 van dit blad heeft Fred de Koning aandacht besteed aan mijn beschouwing in het maartnummer van 2001, waarin ik met name de toetsing van de werking van de interne controle in het kader van de accountantscontrole aan een kritische beschouwing heb onderworpen. Ik vind de bijdrage van De Koning zeer belangwekkend, zij het dat ik zijn visie niet steeds deel. Daarom waag ik mij aan een voortzetting van wat ik hoop dat een bredere discussie wordt.

Eerst zal ik enkele kanttekeningen plaatsen bij zijn aanloop naar het pièce de résistance van zijn betoog, met name aan zijn voorafgaande beschouwingen over de effectiviteit van het Audit Risk Model en de verbreding van de andacht van inherent risico naar bedrijfsrisico.

De kern van zijn, en mijn, beschouwing betreft het toetsen van de werking van de interne controle. Nadat ik hierop ben ingegaan, besteed ik nog specifieke aandacht aan de beschouwingen van De Koning over enkele controlemiddelen.

\section{De effectiviteit van het Audit Risk Model}

Ten aanzien van het Audit Risk Model koestert De Koning zich, evenals Van Leeuwen en Wallage (2002, paragraaf 1), in paragraaf 2 in de uitspraak van het Panel on Audit Effectiveness (2000, p. ix) 'that the model underpinning financial statement audits general$l y$ is appropriate, waaraan dat Panel overigens toevoegt 'although in need of enhancing and updating'.

Prof. J.H. Blokdijk RA is emeritus-hoogleraar Accountantscontrole aan de Vrije Universiteit Amsterdam. Voorts is hij directeur van J.H. Blokdijk Advies BV en adviseur van accountants en advocaten.
Het Panel geeft echter geen kritische analyse van het model, doch baseert zijn bevindingen op een - uniek - onderzoek van 126 controles, die zijn getoetst in het licht van het model. Daarbij constateert het juist ten aanzien van 'assessing control risk' nogal wat verschillen van inzicht tussen accountants, en zelfs gebreken in de uitvoering. Het Panel beveelt accountantskantoren dan ook aan de effectiviteit van hun werkzaamheden te verbeteren, onder meer ten aanzien van 'designing tests of the operating effectiveness of controls', en 'considering the results of the tests of controls' (paragraaf 2.78). Opvallend is dat deze twee aanbevelingen niet voorkwamen in het conceptrapport van het Panel!

Dit zijn nu juist de wonde plekken waar ik mijn vinger op heb trachten te leggen. Het Panel gebruikt het model als toetssteen, doch toetst het model zelf nauwelijks. De conclusie van De Koning dat de bevindingen van het Panel een belangrijke ondersteuning voor het model betekenen, zal in 'politiek' opzicht wel juist zijn; 'wetenschappelijk' heeft het Panel nauwelijks iets 'bewezen'.

\section{Van inherent risico naar bedrijfsrisico}

Een ander aspect waaraan De Koning aandacht besteedt en dat in de beschouwingen over het Audit Risk Model een steeds grotere rol speelt, is de verbreding van de aandacht van het inherent risico naar het bedrijfsrisico. Van Leeuwen en Wallage (2002, paragraaf 5) tonen zich hier voorstanders van, maar komen uiteindelijk tot de conclusie: 'Kijken wij echter vanuit het perspectief van de accountant naar de betrouwbaarheid van de jaarrekening, dan hebben strategische controls alleen waarde als ook de procescontrols goed zijn opgezet en werken.' Dit ligt in lijn met de conclusie van De Koning (2002, paragraaf 3): 'Vervanging van of minder aandacht voor het internecontrolerisico is echter strijdig met de bevindingen van het Panel on Audit Effectiveness' 
Wat is dan wél de betekenis van de verbreding van de aandacht naar de bedrijfsrisico's? De kranten staan er tegenwoordig vol van: verwachte enorme groei, de aandrift tot het tonen van stijgende kwartaalresultaten, de sterke afhankelijkheid van bestuurdersbeloningen van getoonde resultaten, de risico's van discontinuïteit, en noem maar op. Een systematische inschatting van alle bedrijfsrisico's kan al gauw uitmonden in een onderzoek dat nauwelijks te onderscheiden is van een complete management audit. Dit lijkt mij in verreweg de meeste gevallen sterk overdreven, en dus onnodig duur. Want: wat doet de accountant met geconstateerde bedrijfsrisico's die geen accountantscontrolerisico met zich meebrengen? Een slecht betalingsgedrag in de branche betekent ongetwijfeld een vervelend bedrijfsrisico, maar de accountant vindt langdurig openstaande vorderingen ook wel zonder eerst een studie van de gebruiken in de branche te maken. De les moet mijns inziens zijn: kijk goed naar de omgeving waarin de cliënt opereert, en houd de daarbij waargenomen bedrijfsrisico's in het oog bij de inschatting van het product van inherent en interne-controlerisico; kijk vervolgens verder dan de 'bonnetjes' en beoordeel ook het zakelijk karakter van de transacties. Accountants behoren geen 'blinde vinken' te zijn.

\section{De toetsing van de werking van de interne controle}

De Koning wijdt ook aandacht aan de te beoordelen interne-controlemaatregelen, doch deze beschouwing betreft in feite de opzet en het bestaan. Het kernpunt van mijn beschouwing was echter de werking van de interne controle. Hier constateert De Koning een meningsverschil: 'Als Blokdijk een andere inhoud geeft aan het begrip 'werking van de interne controle', in de zin dat alleen over een goed functionerende interne controle gesproken mag worden als de cijfers juist en volledig zijn, dan is het duidelijk waarom er verschillen van mening zijn.' Dit verbaast mij: wat is dan wél het doel van de interne controle? Dat de voorgeschreven rituelen perfect zijn uitgevoerd, ongeacht de resultaten? De visie van De Koning wordt niet helderder in de volgende zinnen: 'Het gaat er dan niet om de goede werking van de interne controle vast te stellen, maar om vast te stellen dat het geheel aan interne-controlemaatregelen permanent tot goede resultaten heeft geleid. Dat kan niet de bedoeling zijn van de beoordeling van de AO/IC.' (2002, paragraaf 5).

Opnieuw rijst de vraag: wat is dan wél de bedoeling van de toetsing van de werking van de interne controle? RAC 400 zegt onder meer: 'om controle-informatie te verkrijgen over de effectiviteit van (....) de werking van de interne-controlemaatregelen gedurende de gehele periode.' De laatste vier woorden zijn van cruciale betekenis: het gaat niet alleen om opzet en (voort)bestaan!

Daarmee kom ik op het tweede punt waarop De Koning een wezenlijk element van mijn beschouwing lijkt te hebben gemist. Ik heb betoogd dat het niet logisch is om voor te schrijven dat de werking van de interne controle gedurende de gehele periode moet worden getoetst als niet tevens wordt verlangd dat de gehele keten van interne-controlemaatregelen in het onderzoek wordt betrokken (2001, paragraaf 3). De Koning geeft een hele matrix van controletechnieken voor verschillende kwaliteitsaspecten (2002, slot paragraaf 5) zonder aannemelijk te maken dat hiermee de gehele periode wordt afgedekt, en zeker zonder aannemelijk te maken dat hiermee de gehele keten wordt bestreken. Om de deugdelijkheid van het Audit Risk Model in dit opzicht te onderbouwen, zou De Koning moeten aantonen ófwel dat vorenstaande twee doelen met zijn controletechnieken worden bereikt, ófwel dat dit niet nodig is voor een sluitende conclusie over de werking van de interne controle. Anders is zijn matrix slechts een lijstje van mogelijke rituelen.

Weliswaar onderkent hij dat ik 'een' controle op de goede werking van de interne controle (op de toegangsbeveiliging) heb ontdekt, maar hij miskent dat het er maar ééntje was. Ik heb dan ook niet de pretentie gehad dat hiermee het gehele probleem van de toetsing van de werking van de interne controle was opgelost; immers, een geautoriseerde functionaris kan gemakkelijker met gegevens knoeien dan een ongeautoriseerd persoon.

Een sluitend stelsel van - uiteraard eventueel steekproefsgewijs uit te voeren - maatregelen ter toetsing van de werking van de interne controle heb ik nog nimmer aangetroffen; de literatuur geeft slechts fragmentarische controles. Ik betwijfel zelfs of zo'n sluitend stelsel in beginsel mogelijk is. Daarmee kom ik op het derde wezenlijke punt waar De Koning niet op ingaat.

Dit is het volgende. Ik heb betoogd dat de voorgestelde maatregelen ter toetsing van de werking van de interne controle welke zinnig en uitvoerbaar lijken, beter kunnen worden gebruikt om het gegevensgericht onderzoek rechtstreeks te richten op posten die de aandacht lijken te verdienen dan om een inschatting van het interne-controlerisico bij te stellen op basis waarvan dan een (grotere of kleinere) blinde steekproef wordt getrokken. Daarom heb ik bepleit de toetsing van de werking van de interne controle als onderdeel van de risicoanalyse te schrappen, en 
bedoelde werkzaamheden te scharen onder de 'richtinggevende procedures' waartoe ook de cijferanalyse behoort. Ik denk dat dit in lijn ligt met de aanbeveling van het Panel on Audit Effectiveness om wat meer 'forensic-type' werkzaamheden te verrichten (2000, p. x). De Koning heeft mij nog niet op andere gedachten gebracht.

\section{Enkele controlemiddelen}

5

De Koning besteedt ook veel aandacht aan de controlemiddelen. Allereerst meldt hij dat programmawijzigingen op de productie-library kunnen worden gelogd (2002, paragraaf 5). Dat is belangrijk, want dit mogelijke controlemiddel was mij (en mogelijk ook andere accountants) tot dusverre onbekend; het is goed dat dit nu in de literatuur van de accountantscontrole verschijnt. Het lijkt mij dat hiermee ook incidentele wijzigingen in de gebruikte programmatuur kunnen worden ontdekt, zodat dit een effectief middel ter toetsing van de werking van de interne controle zou kunnen zijn. Het komt mij echter voor dat de gegevensgerichte controle ook bij de ontdekking van een incidentele wijziging beter op de resultaten van de desbetreffende productierun kan worden gericht, zoals ik eerder heb betoogd ten aanzien van ongeautoriseerde toegang. Hoewel deze controlemogelijkheid van minder belang is indien gebruikers parameters in systemen kunnen instellen of wijzigen (Blokdijk, 2001, paragraaf 2), acht ik deze bijdrage van De Koning toch van betekenis. Evenals mijn 'ontdekking' van de mogelijkheden van controle op de toegangsbeveiliging is dit méér dan waartoe vele schrijvers van leerboeken zijn gekomen (Blokdijk, 2001, paragraaf 1). Hiermee blijkt maar weer hoe nuttig eigen 'uitvindingen' van praktiserende accountants voor de ontwikkeling van de theorie kunnen zijn.

Overigens heb ik in dat kader de mogelijkheid genoemd dat de $\mathrm{AO} / \mathrm{IC}$ van de cliënt de toepassing van genoemd onderzoek in het kader van de toegangsbeveiliging niet waterdicht maakt; dit geldt vermoedelijk ook voor vorengenoemde vondst van De Koning ten aanzien van de controle op programmawijzigingen. In dat kader vraagt De Koning zich af waar de 'natuurlijke adviesfunctie' van de accountant blijft. Dit getuigt niet van realiteitszin: die functie brengt geen bevelsbevoegdheid met zich mee. Cliënten plegen niet altijd (onmiddellijk) te doen wat de accountant aanbeveelt.

Bij zijn afwijzing van mijn kritiek op de wel in RAC 400 genoemde en door de schrijvers van leerboeken herkauwde controlemiddelen (onderzoek van docu- menten, informeren naar en waarnemen van de uitvoering van interne-controlemaatregelen, en opnieuw uitvoeren), verliest De Koning enkele facetten uit het oog.

De (vele) documenten die hij noemt liggen niet 'ten grondslag aan bepaalde transacties of andere gebeurtenissen', zoals RAC 400 in paragraaf 30 eist. Al deze documenten hebben een algemeen karakter, en zeggen dus hooguit iets over de opzet en het (voort)bestaan van het stelsel van $\mathrm{AO} / \mathrm{IC}$, niet over de werking van de gehele keten gedurende de gehele periode. De effectiviteit van dit controlemiddel voor de toetsing van de werking van de interne controle is daarmee niet aangetoond.

Hetzelfde geldt voor het informeren naar en het waarnemen van de maatregelen van interne controle. Hierover zijn zelfs sommige schrijvers van leerboeken sceptisch (Blokdijk, 2001, paragraaf 3). De voorbeelden die De Koning noemt (fysieke beveiliging, backupprocedures, uitwijktests) hebben alle te maken met de algemene beveiliging, en niet rechtstreeks met specifieke posten in de jaarrekening; zij zijn in wezen toekomstgericht. Het kan nut hebben dat ook de accountant helpt nagaan of de beveiligingsmaatregelen werken, bijvoorbeeld door 'legal hacking' of het bijwonen van een uitwijktest, maar hij kan er geen argument in vinden om het interne-controlerisico lager in te schatten.

Bij het opnieuw uitvoeren van maatregelen van interne controle versterkt De Koning in wezen mijn betoog. Hij stelt dat het oordeel van de accountant vaak niet verder kan reiken dan de constatering dat de interne controle lijkt te hebben gewerkt, door onvoldoende technische of commerciële deskundigheid. Ook vervalsing van documenten en parafen kan de accountant niet altijd ontdekken. Dat heb ik ook altijd betoogd: vele maatregelen van interne controle zijn onvervangbaar door de accountant; vandaar het kwalitatief axiomatisch voorbehoud. Maar de logische conclusie is dan dat de toetsing van de werking van die maatregelen niet mogelijk is, en dus dat de onvervangbare interne controle bij de risicoanalyse in elk geval buiten beschouwing moet blijven. Ik had gehoopt dat De Koning die conclusie zou onderschrijven.

\section{Conclusies}

Het Panel on Audit Effectiveness (2000) concludeert in paragraaf 1.13: 'Thus, examining the efficacy of the audit process alone is not the answer to assessing audit effectiveness.' Dit is juist, want effectiviteit gaat vooraf aan efficiency: men moet eerst het doel bereiken alvo- 
rens men zich kan afvragen of dit niet handiger, sneller en goedkoper kan. De effectiviteit van de toetsing van de werking van de interne controle is niet aangetoond, en aan sterke twijfel onderhevig. Het is voorshands een 'geloof', dat wordt beleden met de uitvoering van 'rituelen'. Dit geldt in elk geval voor het onderzoek naar de werking van onvervangbare maatregelen van interne controle.

De toetsing van de werking van de interne controle is bovendien slechts een tussenstation op weg naar het einddoel: de controle van de getrouwheid van de weergave van de financieel-economische gevolgen van het beheer. Dit tussenstation kan worden vermeden door een andere route te kiezen, en wel door in de 'richtinggevende procedures' naast de cijferanalyse ook organisatiegerichte controlemaatregelen op te nemen.

Daarmee zou een effectiever model van de accountantscontrole ontstaan. Eerst dan kan de zoektocht naar grotere efficiency aanvangen (Panel on Audit Effectiveness, 2000, paragraaf 1.13).

\author{
Literatuur \\ Blokdijk, J.H., (2001), De effectiviteit van de systeemgerichte aanpak in de \\ accountantscontrole, in: Maandblad voor Accountancy en bedrijfsecono- \\ mie, maart 2001, pp. 71-80. \\ Koning, W.F. de, (2002), Beoordeling van de interne controle in het kader \\ van de accountantscontrole, in: Maandblad voor Accountancy en bedriffs- \\ economie, juni 2002, pp. 272-280. \\ Leeuwen, O.C. van en Ph. Wallage, (2002), Moderne controlebenaderin- \\ gen steunen op interne beheersing, in: Maandblad voor Accountancy en \\ bedrijfseconomie, maart 2002, pp. 82-90. \\ Panel on Audit Effectiveness of the Public Oversight Board, (2000), Report \\ and Recommendations, August 2000 (www.pobauditpanel.org).
}

\section{Naschrift Fred de Koning}

Het lijkt mij goed, dat er weer eens een fundamentele discussie ontstaat over de principes van accountantscontrole. Het poldermodel leek ook te hebben toegeslagen in ons vakgebied. Wat waren wij het allemaal met elkaar eens! Het ter discussie stellen van de uitgangspunten voor de accountantscontrole is een van de mogelijkheden het vak een wetenschappelijk karakter te geven en bovendien de literatuur aantrekkelijker te maken voor studenten en beroepsbeoefenaren. Wij moeten dan wel duidelijk maken, waar de discussie feitelijk om gaat.

Het was niet, en is nog steeds niet, mijn intentie het Audit Risk Model ter discussie te stellen, zeker niet na kennis te hebben genomen van de bevindingen van het Panel on Audit Effectiveness, dat een van de weinige serieuze empirische onderzoeken op het gebied van accountantscontrole heeft uitgevoerd ${ }^{1}$.

Ik ben het met Blokdijk eens dat uitbreiding van het inherent risico naar het bedrijfsrisico al gauw kan leiden tot sterk overdreven en onnodig dure onderzoeken. Mijn angst is bovendien dat dit ten koste kan gaan van het onderzoek naar het interne-controlerisico, waar naar mijn inschatting in de praktijk toch al te weinig aandacht aan wordt besteed.

Ook over de doelstelling van het toetsen van de werking van de interne controle kan weinig verschil van mening bestaan. Ik onderschrijf dat het erom moet gaan een oordeel te verkrijgen over de effectiviteit van de werking van de interne-controlemaatregelen gedurende de gehele periode. Waar de kern van de discussie ligt, is de opvatting van Blokdijk dat het niet logisch is om voor te schrijven dat de werking van de interne controle gedurende de gehele periode moet worden getoetst als niet tevens wordt verlangd dat 'de gehele keten van interne-controlemaatregelen' in het onderzoek wordt betrokken. Deze logica ontgaat mij. Wij hebben het hier over twee verschillende zaken: de periode, waarin de interne-controlemaatregelen gefunctioneerd hebben, en de strekking van de interne controle, dat wil zeggen de processen of cijfers, waar de interne controle op gericht is.

In eerste instantie ging de discussie vooral over de vraag hoe ver je moet gaan met het beoordelen van de interne controle gedurende de gehele periode. Moet je absolute zekerheid hebben, dat de interne controle permanent tot goede resultaten leidt of mag je steekproefsgewijs vaststellen, dat de interne controle op een aantal willekeurig gekozen momenten goed heeft gefunctioneerd? Om redenen van effciency gaat mijn voorkeur uit naar de laatstgenoemde benadering. Blokdijk lijkt meer naar de eerste benadering te neigen. Zeker in een geautomatiseerde omgeving zijn er voldoende mogelijkheden om vast te stellen dat de interne controle op een aantal willekeurig gekozen momen- 
ten goed heeft gefunctioneerd. Denk daarbij aan de controleerbare vastleggingen, die ontstaan bij een goed opgezette procedure voor change management, testverslagen, vastleggingen van toegekende autorisaties, logging van verkregen toegang tot bestanden en programma's, et cetera.

Wellicht is het probleem dat veel accountants te weinig zicht hebben op de mogelijkheden, die zich op dat terrein voordoen. De gangbare literatuur over auditing laat het op dat punt ook een beetje afweten. Zo zien wij dat Knechel slechts zeer summier (Appendix A bij hoofdstuk 8, pp. 246-251) aandacht besteedt aan de gevolgen van automatisering voor de interne controle. Hij vermeldt daarbij terecht: 'This overview is not intended to be comprehensive or technical. Additional technical background can be obtained form any of a number reference texts.' Wellicht wordt zijn gebrek aan aandacht voor automatisering veroorzaakt door zijn preoccupatie met 'business riks'. Bij Messier vinden wij iets meer aandacht voor automatiseringsaspecten, zij het dat het realiteitsgehalte van zijn aanbevelingen te wensen over laat; wat bijvoorbeeld te denken van de Audit Procedure: 'Review manufacturers' documentation to determine what hardware controls are available' (p. 251)? Meer onderzoek op dit terrein is zeker wenselijk.

Blokdijk legt in zijn reactie veel nadruk op de strekking van de interne controle. Naar zijn mening is het noodzakelijk een oordeel te verkrijgen over de gehele keten van interne-controlemaatregelen. Dat is mijns inziens een misvatting. Neem bijvoorbeeld een geautomatiseerd inkoopproces: Inkopen worden automatisch gegenereerd op basis van voorraadhoogten en verbruikscijfers. De inkooporders worden door middel van een e-commerce automatisch bij de leverancier geplaatst. De leverancier levert de goederen af bij het magazijn, waar een magazijnbediende de barcodes van de inkomende goederen inscant, waarna zij door het systeem als ontvangst worden geboekt. $\mathrm{Na}$ enige tijd ontvangt de administratie van de leverancier een factuur, die wordt gecontroleerd met de in het systeem vastgelegde ontvangst, vervolgens wordt ingeboekt en na verloop van de betaaltermijn automatisch wordt betaald.

Belangrijke schakels in dit inkoopproces zijn uit het oogpunt van interne controle:

1 het geautomatiseerde inkoopsysteem, met name het genereren van inkooporders en het matchen van ontvangsten met openstaande inkooporders;

2 het registreren van goederenontvangsten;

3 het inboeken van ontvangen facturen;

4 het geautomatiseerde betaalsysteem.
De goede werking van de in de sub 1 en sub 4 genoemde systemen opgenomen procedures kan op indirecte wijze worden vastgesteld door beoordeling van de opzet en werking van het change management. Het handhaven van de functiescheiding tussen inkoop, magazijn en administratie kan worden gecontroleerd door beoordeling van opzet en werking van het systeem voor logische toegangsbeveiliging. De sub 3 genoemde schakel moet waarschijnlijk gegevensgericht worden gecontroleerd: een assistent controleert een aantal inkoopfacturen, waarbij met name wordt gelet op: authenticiteit van de factuur, datum, omschrijving, overeenstemming met de geboekte ontvangst, boeking op de juiste grootboekrekening en boeking op de juiste crediteur.

Conclusie: de controle op het inkoopproces wordt uitgevoerd met een combinatie van gegevensgerichte en systeemgerichte controles. Indien Blokdijk zijn aandacht vooral op de factuurcontrole zou willen richten (de gegevensgerichte controle), dan zou hij daarbij tot de teleurstellende conclusie komen dat op de factuur geen blokstempel meer wordt geplaatst, waarin verschillende functionarissen paraferen voor de door hen verrichte (controle)handelingen. Ook zijn er geen uitgeprinte bestelorders meer. Handhaving van de functiescheiding (een onvervangbare controle) kan dus niet meer worden gecontroleerd met gegevensgerichte controles.

De achterliggende gedachte bij het Audit Risk Model is dat een volledige zekerheid over financiële verantwoordingen doorgaans niet of slechts tegen onaanvaardbaar hoge kosten kan worden verkregen, met andere woorden: de accountant loopt altijd een risico dat zijn oordeel onjuist is. Doelstelling van het model is nu dit risico te minimaliseren bij aanvaardbare kosten. Daarbij ontkomt de accountant er niet aan gebruik te maken van hetgeen intern al is gedaan om de betrouwbaarheid van de cijfers te bevorderen in de vorm van interne-controlemaatregelen. Deze maatregelen dragen bij aan de betrouwbaarheid van de cijfers, maar kunnen geen volledige zekerheid bieden. De accountant zal altijd aanvullende gegevensgerichte controles moeten uitvoeren. Waar het in feite om gaat, is het kunnen inschatten van de mate van betrouwbaarheid, die door de interne-controlemaatregelen wordt geboden. Deze mate van betrouwbaarheid bepaalt de aard en de omvang van de gegevensgerichte controles, die de accountant aanvullend dient uit te voeren. Dit is in lijn met de opvattingen van het Panel on Audit Effectiveness: 'The model requires auditors to gain an understanding of a company's internal controls, and to test their effectiveness if the 
auditor intends to rely on them when considering the nature, timing and extent of the substantive tests to be carried out.' (p. 164).

In veel organisaties (denk eens aan de financiële sector) is accountantscontrole overigens volslagen onmogelijk zonder gebruik te maken van hetgeen intern wordt gedaan om de betrouwbaarheid van het cijfermateriaal te bevorderen. Verzekeringspremies, transactiekosten bij effectentransacties, intrest over bankrekeningen, uitkeringen sociale verzekeringen, et cetera, hoe kun je dit in vredesnaam nog gegevensgericht controleren? De accountant ontkomt er niet aan zich een oordeel over de kwaliteit van systemen en daarin opgenomen interne-controlemaatregelen te vormen. Al tientallen jaren worden computers gebruikt bij financiële instellingen, de overheid en grote bedrijven. Tegenwoordig gebruikt iedere organisatie waar accountants over de vloer komen computers. Accountants kunnen daar toch niet in een wijde boog omheen blijven lopen, terwijl organisaties er steeds afhankelijker van worden en de systemen bovendien steeds complexer worden? Meer en meer ontbreken ook de documenten, die 'aan bepaalde transacties ten grondslag liggen'. Denk bijvoorbeeld eens aan e-commerce.

De Richtlijnen voor de Accountantscontrole stellen: 'Er zal altijd sprake zijn van enig interne controlerisico vanwege de onvermijdelijke beperkingen die aan elke administratieve organisatie en interne controle zijn verbonden.' ( p. 343). Blokdijk lijkt er naar te streven deze onzekerheid geheel te vermijden. Echter, indien de interne controles absolute zekerheid over het cijfermateriaal zouden kunnen bieden, dan zouden gegevensgerichte controles tot het verleden gaan behoren. Dat is nog toekomstmuziek, voorlopig moeten wij ons behelpen met een 'optimale mix van controlemiddelen'...

\section{Literatuur}

Knechel, E. Robert, (2001), Auditing Assurance \& Risk, 2nd edition.

Messier, William F., (1999), Audit \& Assurance Services, A systematic approach, 2nd edition.

\section{Noot}

1 Blokdijk heeft gelijk met de constatering, dat de bevindingen van het Panel on Audit Effectiveness in wetenschappelijk opzicht niet volledig onderbouwd zijn. Echter, wat dat betreft is het makkelijk scoren in het vakgebied accountantscontrole. Ook de uitspraken van Blokdijk gaan feitelijk niet verder dan beschouwingen van een (prominent) beroepsbeoefenaar... 